\title{
International Comparison of Six Basic eHealth Indicators Across 14 Countries: An eHealth Benchmarking Study
}

\author{
Elske Ammenwerth ${ }^{1}$ Georg Duftschmid ${ }^{2}$ Zaid Al-Hamdan ${ }^{3}$ Hala Bawadi ${ }^{4}$ Ngai T. Cheung ${ }^{5}$ \\ Kyung-Hee Cho ${ }^{6}$ Guillermo Goldfarb ${ }^{7}$ Kemal H. Gülkesen ${ }^{8} \quad$ Nissim Harel $^{9}$ Michio Kimura $^{10}$ \\ Önder Kırca ${ }^{11}$ Hiroshi Kondoh ${ }^{12}$ Sabine Koch ${ }^{13}$ Hadas Lewy $^{14}$ Dara Mize $^{15}$ Sari Palojoki ${ }^{16}$ \\ Hyeoun-Ae Park ${ }^{17}$ Christopher Pearce ${ }^{18}$ Fernan G. B. de Quirós ${ }^{19}$ Kaija Saranto ${ }^{20}$ \\ Christoph Seidel $^{21}$ Vivian Vimarlund ${ }^{22}$ Martin C. Were ${ }^{23}$ Johanna Westbrook ${ }^{24}$ Chung P. Wong ${ }^{25}$ \\ Reinhold Haux ${ }^{26, *}$ Christoph U. Lehmann ${ }^{27, *}$
}

${ }^{1}$ Institute of Medical Informatics, University for Health Sciences, Medical Informatics and Technology (UMIT), Hall in Tirol, Austria

${ }^{2}$ Section for Medical Information Management, Medical University of Vienna, Vienna, Austria

${ }^{3}$ Faculty of Nursing/WHO Collaborating Center, Jordan University of Science and Technology, Irbid, Jordan

${ }^{4}$ Maternal and Child Health Nursing Department, The University of Jordan, Amman, Jordan

${ }^{5}$ Hospital Authority, Hong Kong

${ }^{6}$ Seoul National University, Korea

${ }^{7}$ Medical Informatics, Hospital de Niños Ricardo Gutiérrez, Ciudad Autónoma de Buenos Aires, Buenos Aires, Argentina

${ }^{8}$ Department of Biostatistics and Medical Informatics, Medical Faculty, Akdeniz University, Antalya, Turkey

${ }^{9}$ Department of Computer Science, Holon Institute of Technology, Holon, Israel

10 Medical Informatics Department, School of Medicine, Hamamatsu University, Shizuoka, Japan

${ }^{11}$ Department of Clinical Oncology, Memorial and Medstar Oncology Center, Antalya, Turkey

12 Department of Medical Informatics, Tottori University Hospital, Yonago, Japan

13 Department of Learning, Informatics, Management and Ethics, Health Informatics Centre, Karolinskalnstitutet, Stockholm, Sweden

${ }^{14}$ Digital Health Ventures, Holon Institute of Technology, Holon, Israel

${ }^{15}$ Department of Biomedical Informatics, Vanderbilt University, Nashville, Tennessee, United States

Methods Inf Med 2020;59:e46-e63.
Address for correspondence Elske Ammenwerth, Institute of Medical Informatics, University for Health Sciences, Medical Informatics and Technology, Eduard WallnöferZentrum 1, 6060 Hall in Tirol, Hall in Tirol, Austria (e-mail: elske.ammenwerth@umit.at).

${ }^{16}$ Department of Health and Social Management, University of Eastern Finland, Kuopio, Finland

${ }^{17}$ College of Nursing, Seoul National University, Seoul, South Korea

18 Director of Research, Outcome Health, Blackburn, Australia

19 Department of Health Informatics, Hospital Italiano de Buenos Aires, Buenos Aires, Argentina

${ }^{20}$ Department of Health and Social Management, University of Eastern Finland, Kuopio, Finland

21 Division of eHealth, Digitalisation and Social Health Economy, Lower Saxony Ministry for Social Affairs, Health and Equal Opportunities, Hannover, Germany

${ }^{22}$ Department of Computer and Information Science, Linköping University, Linköping, Sweden

${ }^{23}$ Vanderbilt University Medical Center, Nashville, Tennessee, United States

${ }^{24}$ Centre for Health Systems and Safety Research, Australian Institute of Health Innovation, Faculty of Medicine and Health Sciences, Macquarie University, Macquarie, Australia

${ }^{25}$ Hong Kong Society of Medical Informatics, Hong Kong

26 Peter L. Reichertz Institute for Medical Informatics, TU Braunschweig and Hannover Medical School, Braunschweig, Germany

${ }^{27}$ Clinical Informatics Center, Department of Pediatrics, Bioinformatics, and Population and Data Sciences, University of Texas Southwestern, Dallas, Texas, United States

\section{Abstract}

* Joint senior authorship.

received

March 14, 2020

accepted after revision

June 21,2020
Background Many countries adopt eHealth applications to support patient-centered care. Through information exchange, these eHealth applications may overcome institutional data silos and support holistic and ubiquitous (regional or national) information logistics. Available eHealth indicators mostly describe usage and acceptance of eHealth in a country. The eHealth indicators focusing on the cross-institutional availability of patient-related information for health care professionals, patients, and care givers are rare. 
Keywords

- health information exchange

- health information systems

- continuity of patient care

- patient-centered care

- eHealth

- international health
Objectives This study aims to present eHealth indicators on cross-institutional availability of relevant patient data for health care professionals, as well as for patients and their caregivers across 14 countries (Argentina, Australia, Austria, Finland, Germany, Hong Kong as a special administrative region of China, Israel, Japan, Jordan, Kenya, South Korea, Sweden, Turkey, and the United States) to compare our indicators and the resulting data for the examined countries with other eHealth benchmarks and to extend and explore changes to a comparable survey in 2017. We defined "availability of patient data" as the ability to access data in and to add data to the patient record in the respective country.

Methods The invited experts from each of the 14 countries provided the indicator data for their country to reflect the situation on August 1, 2019, as date of reference. Overall, 60 items were aggregated to six eHealth indicators.

Results Availability of patient-related information varies strongly by country. Health care professionals can access patients' most relevant cross-institutional health record data fully in only four countries. Patients and their caregivers can access their health record data fully in only two countries. Patients are able to fully add relevant data only in one country. Finland showed the best outcome of all eHealth indicators, followed by South Korea, Japan, and Sweden.

Conclusion Advancement in eHealth depends on contextual factors such as health care organization, national health politics, privacy laws, and health care financing. Improvements in eHealth indicators are thus often slow. However, our survey shows that some countries were able to improve on at least some indicators between 2017 and 2019. We anticipate further improvements in the future.

\section{Introduction}

Modern health care strongly depends on the availability of health-related information. Information and communication systems, which form the technical foundation of eHealth, are thus increasingly introduced in health care institutions worldwide.

The aim of eHealth is to increase the quality and efficiency of care, reduce costs for clinical services, reduce administrative costs of the health care system, and enable new models of health care delivery. ${ }^{1}$ Evidence shows that eHealth can support the quality and efficiency of patient care., ${ }^{2,3}$

In many countries, we can see a shift from institutioncentered to patient-centered information processing. This means that the fragmented pieces of a patient's health data distributed in isolated silos throughout the different institutions involved in his/her care are now consolidated within a common patient record, which integrates data across the boundaries of health care institutions. ${ }^{4}$ eHealth, which is understood as "a commitment for networked, global thinking, to improve health care locally, regionally, and worldwide, ${ }^{5}$ facilitates this shift.

Countries show different progress using eHealth to support information exchange and patient-centered information processing. International organizations have designed and deployed eHealth indicators to explain differences between countries. For example, the Organization for Economic Cooperation and Development (OECD) has developed a guide for measuring eHealth indicators. ${ }^{1}$ The Nordic eHealth Research Network published eHealth indicators to be used in the Nordic region. ${ }^{6,7}$ The European Commission publishes a report on the dissemination of eHealth functionality among general practitioners within the European Union (EU) member states in every 5 years. ${ }^{8}$ The World Health Organization (WHO) provides statistics for several eHealth indicators in European member countries. ${ }^{9}$ In the United States, the electronic health record (EHR) meaningful use incentive program requires participating care providers to demonstrate fulfillment of several functionality criteria as a prerequisite for receiving incentive payments. ${ }^{10}$

While these eHealth benchmarking approaches give important insights into eHealth adoption in different countries, they are not able to provide a clear picture of the cross-institutional availability of clinical information for clinicians and patients. Clinical information is at the core of eHealth and its availability to clinicians and patients across institutional boundaries is a precondition for patient-centered care.

In this paper, we apply six eHealth indicators and present the results of these indicators in 14 countries. We then compare our approaches to other available eHealth benchmarks.

\section{Objectives}

This study was aimed to present eHealth indicators on crossinstitutional availability of major types of patient data for health care professionals and patients and their caregivers across 14 countries. "Availability of patient data" was defined as having the ability to access data and to add data to the patient record. 
This study also focused to extend and to highlight changes for those seven countries that already participated in the eHealth indicator survey in 2017..$^{11}$

Comparing our indicators and the resulting data for the examined countries with other related eHealth benchmarks was also studied.

\section{Methods}

\section{Indicators and Survey Instrument}

The survey instrument focuses on six basic eHealth indicators that cover two major aspects. First, the immediate access of health care professionals, patients, and (informal) caregivers (e.g., relatives) to patients' major relevant health data stored in EHRs. Second, the possibility of health care professionals, patients, and their caregivers to immediately add data to an EHR.

The indicators were defined and tested in a survey of six countries in 2017. ${ }^{11}$ Details of the development of the items and the underlying motivation for selecting these items have been published. ${ }^{11}$

The survey contains 60 items that we aggregate to the six major eHealth indicators as presented in -Table 1.

Please note that throughout the survey, we chose the following naming conventions:

- EHR: to accommodate for various interpretations of this term in the participating countries, we defined EHR as "any patient-centered electronic collection of clinical data or documents generated as a by-product of patient care." According to ISO 20514 (ISO: International Organization for Standardization), an EHR may be managed by local (institutional) EHR systems, as well as by shared (i.e., transinstitutional, regional, or national) EHR systems.

- Health care institution: a health care institution provides inpatient and/or outpatient care for a patient. We focused on selected health care institutions expected to exist in most participating countries. These institutions include hospitals, medical offices (e.g., physicians in private practice or with health maintenance organization [HMO]), contract(physicians in an ambulatory clinic), nursing homes (institutions for long-term nursing care of elderly or chronically ill patients), outpatient nursing organizations (providing ambulatory nursing care at the patient's home), and pharmacies.

- Major relevant data: EHRs contain a large variety of data elements. We focused on major data elements considered central for patient care, namely, diagnoses, medication, and problems (e.g., allergies).

- Immediate access and immediate adding of data: accessing and adding data are seen as "immediate" if they are available through electronic means and without the need for special requests; paper-based information processing cannot provide this.

- Caregivers: persons informally taking care of patients such as family members or parents (for their children).

\section{Organization of the Survey}

Two experts from each of the following countries were invited to provide the indicator data for their country: Argentina, Australia, Austria, Finland, Germany, Hong Kong, Israel, Japan, Jordan, Kenya, South Korea, Sweden, Turkey, and the United States.

Table 1 Six basic eHealth indicators used in the eHealth indicator survey 2017 and 2019

\begin{tabular}{|l|l|l|}
\hline Abbreviations & eHealth indicator & Explanation \\
\hline AH & $\begin{array}{l}\text { Access of healthcare professionals to their patients' data: } \\
\text { immediate access of physicians, nurses, and pharmacists } \\
\text { to their patients' EHRs' major relevant data from other } \\
\text { health care institutions where the patient received care }\end{array}$ & $\begin{array}{l}\text { The } 21 \text { items assessed whether diagnoses, medication, } \\
\text { and problems documented in one institution were } \\
\text { available for health care professionals in other } \\
\text { institutions. }\end{array}$ \\
\hline AP & $\begin{array}{l}\text { Access of patients to their data:immediate access of } \\
\text { patients to their EHRs' major relevant data from selected } \\
\text { health care institutions where the patient received care }\end{array}$ & $\begin{array}{l}\text { The } 15 \text { items assessed whether diagnoses, medication, } \\
\text { and problems documented by a healthcare institution } \\
\text { were available for the patient. }\end{array}$ \\
\hline AC & $\begin{array}{l}\text { Access of caregivers to patients' data:immediate access } \\
\text { of caregivers to the patients' EHRs' major relevant data } \\
\text { from selected health care institutions where the patient } \\
\text { received care }\end{array}$ & $\begin{array}{l}\text { The 15 items assessed whether diagnoses, medication, } \\
\text { and problems documented by a healthcare institution } \\
\text { were available for authorized caregivers of the patient. }\end{array}$ \\
\hline EH & $\begin{array}{l}\text { Adding data by health care professionals:physicians, nurses, } \\
\text { and pharmacists of selected health care institutions are able } \\
\text { to add data immediately to the patients' EHR(s) }\end{array}$ & $\begin{array}{l}\text { The seven items assessed whether health care profes- } \\
\text { sionals were able to electronically document patient- } \\
\text { related data in a (local or shared) EHR system. }\end{array}$ \\
\hline EP & $\begin{array}{l}\text { Adding data by patients:patients are able to add data } \\
\text { immediately to their EHR(s) }\end{array}$ & $\begin{array}{l}\text { The item assessed whether the patient is able to add data } \\
\text { in electronic form to a (local or shared) EHR system to } \\
\text { make them available to health care professionals and } \\
\text { themselves. }\end{array}$ \\
\hline EC & $\begin{array}{l}\text { Adding data by caregivers:caregivers are able to add data } \\
\text { immediately to the patients' EHR(s) in a respective } \\
\text { country }\end{array}$ & $\begin{array}{l}\text { The item assessed whether the patient's caregivers are } \\
\text { able to add data in electronic form to a (local or shared) } \\
\text { EHR system to make it available to health care profes- } \\
\text { sionals and themselves. }\end{array}$ \\
\hline
\end{tabular}

Abbreviations: AC, access of caregivers to the patients' health record data; AH, access of healthcare professionals to their patients' data; AP, access of patients to their health record data; EC, enabling caregivers to add data to the patients' health record(s); EH, adding data by health care professional (s); EHR, electronic health record; EP, enabling patients to add data to their health record(s).

Note: The explicit scope of all questions was the experts' respective country. 
The rationale behind the selection of the 14 countries was as follows: Seven countries (Austria, Finland, Germany, Hong Kong, South Korea, Sweden, and the United States) already participated in the eHealth indicator survey 2017 and were thus chosen to allow an analysis of an eventual progress made. The remaining seven countries were chosen according to our goal to include representative countries from the remaining three continents (we did not consider Antarctica) and including a broad spectrum of different health care systems and various levels of eHealth adoption. The selection of the experts from each country was based on their known scientific activity in national eHealth projects.

As eHealth activities are advancing in many of these countries, all responses had to reflect the situation in the respective country on August 1, 2019 as date of reference.

The two experts in each participating country were asked to complete the survey, to solve any discrepancies through discussion, and to submit a consensus version. For each item, available answering options were as follows:

- “-": not given, meaning that the respective indicator item is not fulfilled or only fulfilled in a clear minority of institutions, health care professionals, or patients $(<20 \%)$.

- "+": partly given, meaning that the respective indicator item is fulfilled in some (but not all) institutions, health care professionals, or patients.

- "++": given, meaning that the respective indicator item is fulfilled in the large majority of institutions, health care professionals, or patients.

- N/A: not applicable.

The experts were also asked to provide short descriptions for all "partly given" answers and where they saw the need to provide additional context. E.A. and R.H. carefully reviewed and discussed all answers, contacted the experts in the event of clarification needed, and documented revised answers accordingly.

All authors explicitly released the final version of their respective survey results. Complying with rules for good scientific practice, all final questionnaires are available from the corresponding author.

\section{Calculation of Indicators}

-Table 2 summarizes the formulas for the 2019 survey. Based on the 60 items, we calculated the six eHealth indicators for each country using mainly the published formulas and motivations for the 2017 survey $^{11}$ with the following two clarifications:

- Indicator AH (access of healthcare professionals to their patients' data): for pharmacies to achieve an overall "+," it is now sufficient if they have at least access (i.e., "+") to medication data. Rationale: in many countries, there is no plan for pharmacies to have access to diagnoses and problems at all. Thus, grading pharmacies as "-" that have access to medication data, but not to diagnoses and problems, does not seem fair. Therefore, we changed this calculation in the 2019 survey. The changed wording is highlighted in - Table 2.
- Indicator EH (enabling health care professionals to add data to their patients' health record[s]; adding data by health care professionals): we now award an overall "+" if three or more outcome values were at least "+" and one or more outcome value was "N/A." Rationale: In one country (Jordan), not all listed types of health care institutions exist independently, thus "N/A" is a valid answer and calculating it as "-" as in the 2017 survey did not seem adequate. The changed wording is highlighted in - Table 2.

\section{Results}

We received responses from all invited countries. With the exception of Kenya, for all countries, at least two experts provided consensus data.

-Table 3 presents the outcome for the eHealth indicator $\mathrm{AH}$, as well as changes compared to the 2017 survey. Survey responders added additional explanations that are summarized in -Appendix 1.

Overall, four countries (Finland, Hong Kong, Japan, and Sweden) received a "++" in this indicator. Compared to the 2017 survey, Austria, South Korea, and Sweden improved in some items and South Korea, as well as Sweden, also improved their overall indictor $\mathrm{AH}$.

- Table 4 presents the outcome for eHealth indicator AP (access of patients to their health record data) and eHealth indicator AC (access of caregivers to the patients' health record data), as well as changes compared to the 2017 survey. Survey responders added additional explanations that are summarized in -Appendix 2.

Overall, two countries (Finland and South Korea) received a "++" in these indicators. Compared to the 2017 survey, only Austria and Sweden improved some items. In the case of Austria, this led to an improvement of the overall indicators $\mathrm{AP}$ and AC.

-Table 5 presents the outcome for the eHealth indicator $\mathrm{EH}$, as well as changes compared to the 2017 survey. Survey responders added additional explanations that are summarized in -Appendix 3.

Overall, seven countries (Australia, Finland, Israel, Japan, South Korea, Sweden, and the United States) received a "++" in this indicator. Compared to the 2017 survey, Austria and Hong Kong improved some items but without effect on the overall indicator.

-Table 6 presents the outcome for eHealth indicators EP (enabling patients to add data to their health record[s]) and EC (enabling caregivers to add data to the patients' health record[s]), as well as changes compared to the 2017 survey. Survey responders added additional explanations that are summarized in -Appendix 4.

Overall, only Turkey received a "++" in this indicator. Compared to the 2017 survey, no country showed an improved indicator.

-Table 7 summarizes the six eHealth indicators for all countries. No country received a "++" for all indicators. Finland received a "++" for four indicators, South Korea for three indicators, Japan and Sweden for two indicators, and Australia, Hong Kong, Israel, Turkey, and the United States for one indicator. 
Table 2 Indicator definition of the six eHealth indicator survey 2019. Outcome values can be given (++, green), partially given $(+$, yellow) or not given $(-$, red)

\begin{tabular}{|c|c|c|}
\hline No. & Abbreviation & Indicator calculation \\
\hline 1 & $\mathrm{AH}$ & $\begin{array}{l}\text { Calculation of this eHealth indicator is based on } 3 \times 7=21 \text { outcome values:access to }(1) \text { diagnoses, }(2) \\
\text { medication, and ( } 3 \text { problemsfrom hospitals (by }(1) \text { physicians, }(2) \text { nurses, }(3) \text { pharmacists), from (4) medical } \\
\text { offices (by physicians), from (5) nursing homes (by nurses), from (6) outpatient nursing organizations (by } \\
\text { nurses), and from ( } 7 \text { pharmacies (by pharmacists). } \\
\text { Outcome values on access to diagnoses, medication, and problems from each health care institution by the } \\
\text { selected health care professionals were defined as follows: } \\
\text { a) Access is }++ \text { if all three outcome values for diagnoses, medication, and problems are }++ \text { or if two are }++ \\
\text { and one is }+ \text {. } \\
\text { b) Access is }+ \text { if one outcome value is }++ \text { and two are }+ \text { or if all three outcome values are }+ \text {; exception: for } \\
\text { pharmacies, a - was given if the outcome value for medication is at least }+ \text {. } \\
\text { c) Access is }- \text { in all other cases. } \\
\text { Based on the then remaining sevenvalues this eHealth indicator was calculated in the sequence: } \\
\text { 1) Indicator is }++ \text { if } \geq 4 \text { outcome values are }++ \text {. } \\
\text { 2) Indicator is }+ \text { if } \geq 2 \text { outcome values are }++ \text { or } \geq 3 \text { values are }++ \text { or }+ \text {. } \\
\text { 3) Indicator is }- \text { in all other cases. }\end{array}$ \\
\hline 2,3 & AP, AC & $\begin{array}{l}\text { Calculation of these eHealth indicators is based on } 3 \times 5=15 \text { outcome values: } \\
\text { Access to (1) diagnoses, }(2) \text { medication, and }(3) \text { problemsfrom }(1) \text { hospitals, }(2) \text { medical offices, (3) nursing } \\
\text { homes, (4) outpatient nursing organizations, and }(5) \text { pharmacies. } \\
\text { For the values of diagnoses, medication, and problems for each selected health care institution we used the } \\
\text { same definition of values as for indicator } A H_{r} \text {. } \\
\text { Based on the remaining five values this eHealth indicator was calculated in the sequence: } \\
\text { 1) Indicator is }++ \text { if } \geq 3 \text { outcome values are }++ \text { and } \leq 2 \text { outcome values are }-. \\
\text { 2) Indicator is }+ \text { if } \geq 2 \text { outcome values are }++ \text { or }+ \\
\text { 3) Indicator is }- \text { in all other cases. }\end{array}$ \\
\hline 4 & $\mathrm{EH}$ & $\begin{array}{l}\text { This eHealth indicator is based on seven outcome values, adding data in hospitals (by ( } 1) \text { physicians, }(2) \text { nurses, } \\
\text { (3) pharmacists), in (4) medical offices (by physicians), in ( } 5 \text { ) nursing homes (by nurses), in (6) outpatient } \\
\text { nursing organizations (by nurses), and in ( } 7) \text { pharmacies (by pharmacists). } \\
\text { It was calculated in the sequence: } \\
\text { 1) Indicator is }++ \text { if } \geq 4 \text { outcome values are }++ \text {. } \\
\text { 2) Indicator is }+ \text { if } \geq 2 \text { outcome values are }++ \text { or } \geq 4 \text { outcome values are at least }+ \text { or } \geq 3 \text { outcome values are } \\
\text { at least }+ \text { and } \geq 1 \text { outcome value is N/A. } \\
\text { ) Indicator is }- \text { in all other cases. }\end{array}$ \\
\hline 5,6 & EP, EC & ne value itself served as the eHealth indicator. No calculation was necessary. \\
\hline
\end{tabular}

Abbreviations:AC, access of caregivers to the patients' health record data; AH, access of healthcare professionals to their patients' data; AP, access of patients to their health record data; $\mathrm{EC}$, enabling caregivers to add data to the patients' health record(s); $\mathrm{EH}$, adding data by health care professional (s); EP, enabling patients to add data to their health record(s).

Notes: Indicator definitions are taken from the eHealth indicator survey 2017 (p. 708), with two clarifications (underlined; see main text for explanation).

Additional value not applicable is visualized as N/A and in black.

\section{Discussion}

\section{Summary of Findings}

The 14 participating countries demonstrated diverse crossinstitutional availability of patient-related information.

Finland, Hong Kong, Japan, and Sweden provide health care professionals from various inpatient and outpatient organizations with best access to patients' cross-institutional health record data ( - Table 3). Overall, 11 countries offer hospital staff fully or partly access to cross-institutional data, and 10 countries offer this for medical offices. In only six countries, nursing homes and outpatient nursing organizations have access to cross-institutional data. Three countries do not allow any access to any professional group.

Finland and South Korea allow patients and their caregivers the best access to their health record data ( - Table 4), five countries offer at least partial access. In all these countries, patients receive the largest amount of health record data from hospitals and from medical offices, as access to these data is fully or partly offered in seven countries. Access to data from nursing homes is only available in two countries. Three countries allow access to data from outpatient nursing organizations. Six countries do not allow patients and theiry caregivers any access to their data.

In all countries, health care professionals are partly or fully able to add patient data to a patient health record ( - Table 5 ). This reflects the fact that nearly all health care institutions have some sort of organizational EHR system where patient data is documented. Full support for electronic documentation is especially available in hospitals ( 12 countries) and medical offices ( 11 countries), to less extent also in nursing homes ( 5 countries) and outpatient nursing organizations (4 countries). Pharmacies typically only add medication data to the health record.

Only six countries allow patients and their caregivers to add data to the patient EHR, with Turkey supporting this best ( - Table 6 ). Eight countries do not allow patients to add any data.

Finland showed the highest fulfillment of all six analysed eHealth indicators, followed by South Korea, Japan, and 
Comparison of Six Basic eHealth Indicators Across 14 Countries Ammenwerth et al. e51
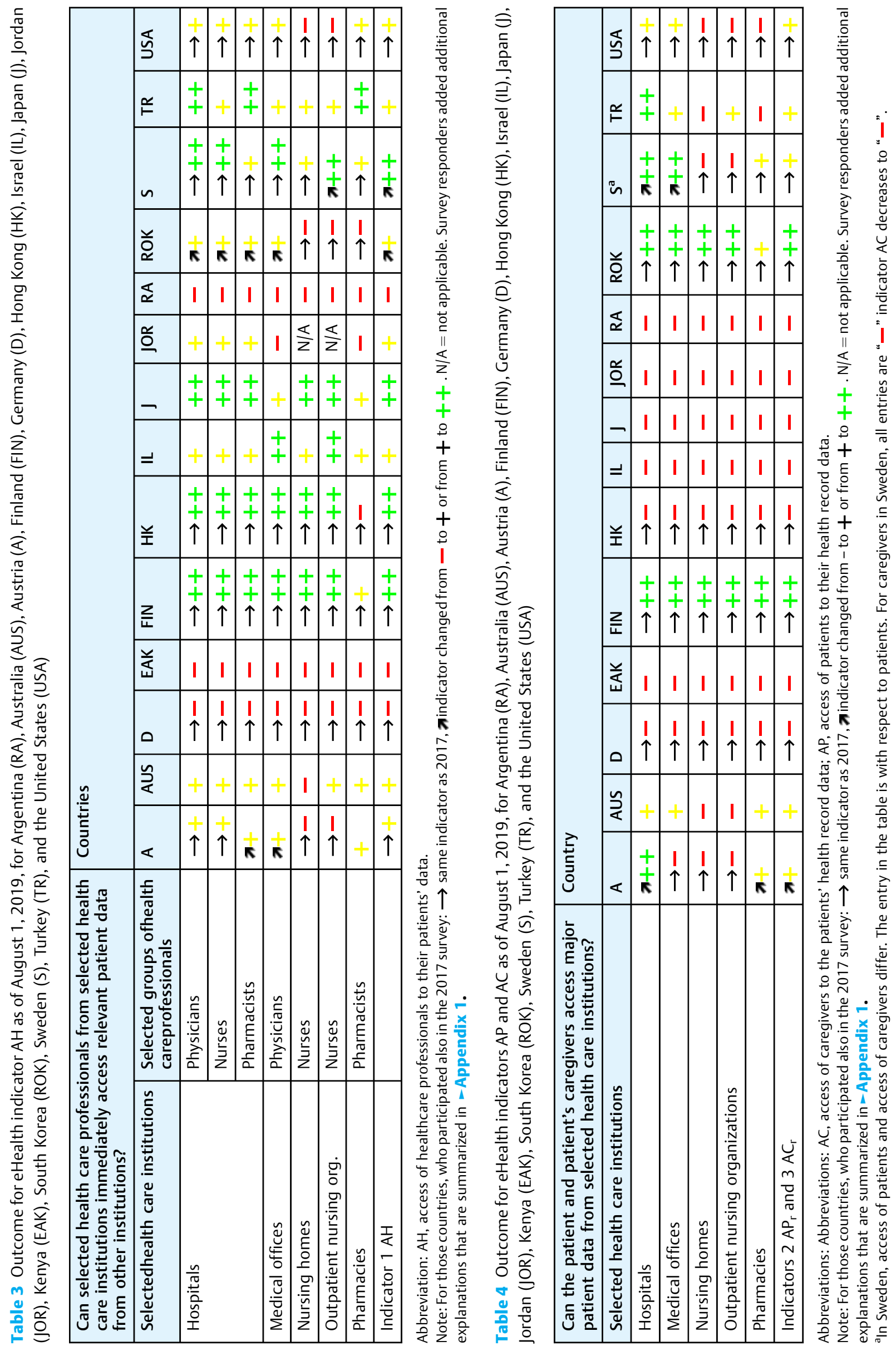

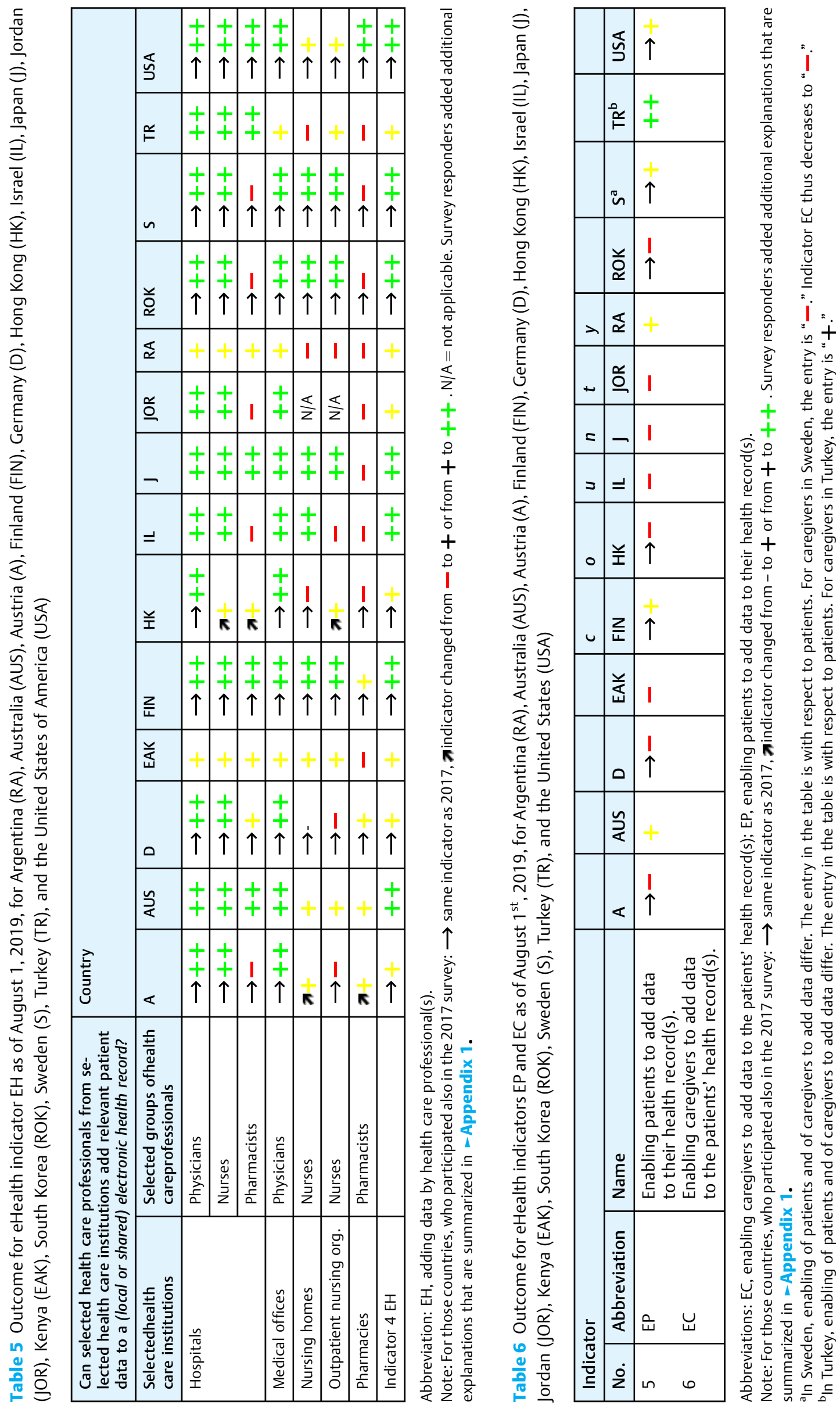
Sweden ( - Table 7). No countries showed full support for all eHealth indicators,indicating opportunities for further improvement in all countries.

The WHO considers eHealth as an integral part of delivering improvements in health and sees a "substantial increase in the number and range of solutions." ${ }^{13}$ Our survey shows that in most of the 14 observed countries, the vision of universal access to major patient data is not yet fully reached. Nevertheless, according to the WHO, there has been a steady growth in the adoption of national EHR systems in the last years. ${ }^{13}$ We found three countries (Argentina, Germany, and Kenya; -Table 3) that did not allow health care professionals interorganizational access to relevant patient data from any of the selected health care institutions. We found six countries (Argentina, Germany, Hong Kong, Japan, Jordan, and Kenya; - Table 4) that did not allow patients and their caregivers to access relevant health record data from any of the selected health care institutions.

Advancement in eHealth depends on contextual factors such as health care organization and health politics. Often cited barriers to national EHR systems are lack of funding, technical infrastructures, human resources capacity, effectiveness, and legal frameworks. ${ }^{13}$ These barriers may hamper fast improvements in eHealth. However, countries like Finland show that strategic planning and long-term investments may result in effective eHealth. eHealth must show a positive impact on costeffectiveness ${ }^{13}$ and on the quality of care ${ }^{14}$ to increase the likelihood of being supported and implemented. Building such an evidencebase on the impact of eHealth seems crucial to further foster advancement in eHealth. $^{15}$

\section{Limitations}

To increase the objectivity of the data, survey responses were based on consensus from two experts for all (but one) country. We tried to select eHealth experts for each country, but other experts may have come to other conclusions. All responses were reviewed and any implausible responses were rechecked with the experts.

Using eHealth expert surveys provided subjective results of the different indicators. Future research should be directed toward more direct measures that can provide a more objective picture by measuring completeness of information in electronic records. Other areas of future work will be to include allied health care providers, as well as professions, who support the health sector such as social workers.

Different from other surveys, ${ }^{16}$ we did not provide quantitative ranges for "-," "+," and "++." Instead, we aimed to make responding easier and accommodate for different interpretations and goals. However, not providing ranges might have led to different interpretation especially of "-" and "+." To avoid this, we asked the experts to choose "-" if less than $20 \%$ of institutions or stakeholders in their country would have a positive indicator.

While attempting to carefully define and explain the core elements such as "EHR," we found that some experts had difficulties to understand the scope of some questions. Based on a different understanding of the term EHR, some 
misunderstanding arose. We tried to accommodate this during verification of the responses through personal contact.

As a general limitation of every survey, the selection of indicators implies a certain perspective (and potential bias), with emphasis on some aspects and lack of coverage of other potentially important aspects. For example, we did not address questions such as the usefulness of EHR data for research.

\section{Changes for Countries that Participated in the Survey of 2017}

The eHealth indicator $\mathrm{AH}$ saw the biggest improvement between surveys with two (South Korea and Sweden) out of seven countries able to raise their overall score compared to the 2017 survey ( - Table 7 ). Considering that AH already showed the second highest overall scores in 2017 ("++" for two countries, "+" for three countries, and two “-”), this additional improvement seems remarkable and reflects better interoperability of electronic records. Hospital-based health care professionals made the most progress in accessing their patients' data (-Table 3 ).

For eHealth indicators AP and AC, only Austria improved its overall score (from "-" to "+"). Most progress could be made in accessing data of hospitals (now "++" in Austria and Sweden, see - Table 4).

For the other three indicators, $\mathrm{EH}, \mathrm{EP}$, and EC, none of the seven countries was able to make any visible improvements. As EH was the top scoring indicator already in 2017 ("++" for four countries and "+" for three countries), this seems less problematic than the stagnation for EP and EC. The latter indicators had low outcomes in 2017 (four "-" and three "+"), suggesting that substantial room for improvement was not exploited.

\section{Comparisons to other eHealth Benchmarks}

The OECD has developed a guide for measuring eHealth indicators. It is currently only available in a draft version. ${ }^{1}$ The guide includes surveys to be answered by caregivers, as well as chief information officers of health institutions. The surveys address the availability of different types of electronic health information (e.g., problem lists, medication lists, and allergies) for caregivers, as well as patients, and distinguish between data-generated inside or outside the own organization. A smaller subset of seven indicators (e.g., management of electronic patient information by primary care providers, exchange of radiology images, and patient access to test results online) was used in a survey performed within 38 countries. ${ }^{16}$ Compared to this OECD eHealth indicator survey, our survey is broader in regard to the included health care institutions by not only covering primary care providers and hospitals but also nursing homes, as these represent important contributors to patient-centered care. Comparable to the OECD survey, we also focused on problem lists, diagnoses, and allergies that we find essential for patient-centered care. The OECD survey, however, adds additional information types, such as demographics and vital signs, which makes the survey somewhat longer.
Six countries were covered both by the OECD survey ${ }^{16}$ and our survey, and thus allowed us to compare the results. For the indicator EH, "enabling to add data," with a focus on primary-care physicians (line 4 in - Table 5), five of these six countries (Austria, Germany, Finland, Israel, and Sweden) scored "++" in our survey and "75 to $100 \%$ " in the OECD survey. Turkey scored "+" in our survey (with the comment that some private offices do not use EHRs) and " > 75\%" in the OECD survey. The survey results thus are congruent.

Regarding the indicator AP/AC, "access to EHR major data by patients or caregivers," with a focus on primary care physicians (line 2 in -Table 4), both surveys reported similarly ("++," respectively, "maturity" for Finland and Israel and "-," respectively, “<50\%" for Germany). For Turkey, our survey found "+" and the OECD survey " $<50 \%$ " that can be seen as corresponding. For Sweden, we found "++" and OECD $<50 \%$." The reason may be the different survey dates (2016 vs. 2019) as in our surveys Sweden scored "+" in 2017 and "+ + " in 2019.

In 2013, the Nordic eHealth Research Network published a specification of eHealth indicators to be used in the Nordic region. ${ }^{6}$ It is based on the OECD work and refines it in several aspects. The specification focused on three indicators for its initial test phase. These indicators address the availability of a list of currently prescribed medications to every caregiver that the patient sees, the availability and use of electronic transmission of medication prescriptions, and the availability and use of secure messaging between caregivers and patients for appointment booking. The initial set of indicators was extended to 49 indicators in $2015,{ }^{7}$ which address the availability and access of various types of health information (e.g., clinical notes, lab results, and medication prescriptions) by caregivers and patients. Comparable to the Nordic eHealth Research Network, our survey focusses on the availability of certain clinical information (e.g., clinical notes, lab results, and medication prescriptions). The Nordic indicator results are, however, limited to Nordic countries, while we covered countries from all over the world.

Two countries provided data in the Nordic survey ${ }^{7}$ and were also covered in our survey, Finland and Sweden. In our survey, Finland scored " ++" for the indicator AH, "access of health care professionals to patient data," with regard to access from hospitals and from medical offices (lines 1-4 in - Table 3). In the Nordic survey, Finland scored high for access to clinical notes (95\%), patient summaries (85\%), and prescriptions (100\%) from specialized care institutions and reasonably high $(78,63$, and $100 \%)$ for access to the same type of information from primary care institutions. Both survey results thus were congruent. In our survey, Sweden scored "++" for the indicator AH with regard to access from hospitals and from medical offices. In the Nordic survey, Sweden scored $100 \%$ for access to clinical notes, patient summaries, and prescriptions both from primary and specialized care institutions. These results thus were also congruent.

The European Commission publishes a report on the dissemination of eHealth functionality among general practitioners (GPs) within the EU member states in a 5-year interval. $^{8}$ This report provides an overview of the usage 
frequency of different types of content within the GP's EHR systems, such as laboratory test results, radiology reports, and drug-related information. In contrast to our survey, it does not focus on cross-institutional access to this data, thus we must expect that answers primarily refer to access within the GPs' local EHR systems. The survey further shows the extent of the exchange of these data with other care providers. Overall, our survey is broader, as we also cover hospitals, pharmacies, and nursing homes.

Four countries (Austria, Germany, Finland, and Sweden) were covered both by the GP survey ${ }^{8}$ and our survey allowing comparison of the results. Regarding indicator $\mathrm{AH}$, with focus on medical offices (line 4 in -Table 3 ), the surveys were congruent with Austria/Finland/Sweden scoring "+"|“++"|“+ +" in our survey and 1.6/2.9/2.9 (out of a maximum of 4 points) for indicator "health information exchange of clinical data" in the GP survey. Germany scored 1.6 points in the GP survey and "-" in our survey. The reasons for the divergent conclusions between Germany (1.6/-) and Austria (1.6/+) in both surveys could be in the recent changes in Austria. At the moment, Austria is introducing the national EHR system ELGA (Elektronische Gesundheitsakte) leading to improvement of the indicator AH to "+" in our survey. ELGA may not have been covered by the GP survey from 2018 .

The WHO provides statistics for several eHealth indicators among the European members of the WHO within its European Health Information Gateway. ${ }^{9}$ The data originated from the WHO's global eHealth survey from $2015{ }^{13} \mathrm{~A}$ separate report is available for the European region. ${ }^{17}$ The indicators primarily focus on issues such as funding, strategies, legislation, and the existence of certain eHealth programs. These WHO indicators thus do not cover the availability of certain types of health information for certain types of caregivers or the patient as our indicators do.

In the United States, the EHR meaningful use incentive program requires participating care providers to demonstrate the satisfaction of several criteria as a prerequisite for funding. ${ }^{10}$ Criteria focus on health information exchange and on providing patients electronic access to their health information. These criteria are more focused on available functionality and less on available Information.

While Esdar et al used an existing diffusion model to calculate the diffusion dynamics of EHRs in German and U.S. hospital care between 2007 and 2017, ${ }^{18}$ access to different types of health information by different types of care providers was not addressed by them.

Naumann et al compared eHealth adoption in Austrian, German, and Swiss hospitals in regard to diffusion of EHRs, health information exchange, and electronic communication with patients. ${ }^{19}$ Similar to the present work, they analyzed the availability of medical discharge letters for external care providers.

Tsai and Koch developed a framework for eHealth evaluation and monitoring in Sweden. ${ }^{20}$ It focuses on 19 specific eHealth outcomes and provides indicators for assessing the outcomes.

Our survey provides an international perspective on the availability of basic clinical data for important stakeholders involved in patient-centered care, including patients and their caregivers. We focus on available and reproducible information and not on functionalities or technical infrastructure. In accordance with the Clinical Adoption Metamodel, ${ }^{21}$ we see availability and usage of information systems as the precondition of information availability which is an important precondition for information logistics ("right information at the right place to the right person"22). Information availability thus is also the precondition to modification of clinical behaviors and clinical decisions that may, in the end, affect patient outcomes.

\section{Conclusion}

Advancement in eHealth depends on contextual factors such as health care organization, national health politics, and health financing. Improvements in eHealth are thus often slow. Our survey shows, however, that some countries were able to improve at least some indicators between 2017 and 2019. Further improvements can be expected in the future. Countries such as Finland show that strategic planning and long-term investments allowed fostering eHealth successfully in the end.

We must remember that the indicators we chose do not directly reflect the quality of health care. Quality of care may be quite high, even when eHealth indicators may (still) be low. Nevertheless, we expect that easy access to relevant patient data is an important part of high-quality patient care.

Conflict of interest

None declared.

Acknowledgments

The authors thank Ute Zeisberg for her support in validating the survey data.

\section{References}

1 Organisation for Economic Co-operation and Development (OECD). Draft OECD Guide to Measuring ICTs in the Health Sector. Available at: https://www.oecd.org/health/health-systems/Draft-oecd-guide-to-measuring-icts-in-the-health-sector.pdf. Accessed July 15, 2020

2 Kruse CS, Beane A. Health information technology continues to show positive effect on medical outcomes: systematic review. J Med Internet Res 2018;20(02):e41

3 Hersh WR, Totten AM, Eden KB, et al. . Outcomes from health information exchange: systematic review and future research needs. JMIR Med Inform 2015;3(04):e39

4 Kuhn KA, Giuse DA. From hospital information systems to health information systems. Problems, challenges, perspectives. Methods Inf Med 2001;40(04):275-287IS

5 Eysenbach G. What is e-health? J Med Internet Res 2001;3(02):E20

6 Hyppönen H, Faxvaag A, Gilstad H, et al. . Nordic eHealth indicators: organisation of research, first results and plan for the future. Stud Health Technol Inform 2013;192:273-277

7 Nordic Council of Ministers. Nordic EHealth Benchmarking. Available at: https://norden.diva-portal.org/smash/get/diva2:10 93162/FULLTEXT01.pdf. Accessed July 25, 2020

8 European Commission. Benchmarking Deployment of EHealth among General Practitioners. Available at: http://ec.europa.eu/ information_society/newsroom/cf/dae/document.cfm?doc_id=4 897. Accessed July 15, 2020 
9 World Health Organization. E-health: Indicators \& visualizations. Available at: https://gateway.euro.who.int/en/themes/e-health/ indicators-visualizations/. Accessed July 15, 2020

10 Centers for Disease Control and Prevention. Public Health and Promoting Interoperability Programs. Available at: https://www. cdc.gov/ehrmeaningfuluse/introduction.html. Accessed July 15, 2020

11 Haux R, Ammenwerth E, Koch S, et al. A Brief Survey on Six Basic and Reduced eHealth Indicators in Seven Countries in 2017. Appl Clin Inform. 2018;9(3):704-713. doi:10.1055/s-0038-1669458

12 ISO. ISO/TR 20514:2005. Health informatics-Electronic health record-Definition, scope and context. Available at: https://www. iso.org/standard/39525.html. Accessed July 15, 2020

13 World Health Organization. Global Diffusion of EHealth: Making Universal Health Coverage Achievable. Available at: https://apps. who.int/iris/bitstream/handle/10665/252529/9789241511780-eng. pdf;jsessionid=B7E7B4CF6BA92C6F4CC674C962BC395B?sequence $=1$. Accessed July 15, 2020

14 Granja C, Janssen W, Johansen MA. Factors determining the success and failure of ehealth interventions: systematic review of the literature. J Med Internet Res 2018;20(05):e10235. Doi: 10.2196/10235

15 Rigby M, Ammenwerth E, Talmon J. Forward outlook: the need for evidence and for action in health informatics. Stud Health Technol Inform 2016;222:355-363. Doi: 10.3233/978-1-61499-635-4-355

16 Zelmer J, Ronchi E, Hyppönen H, et al. . International health IT benchmarking: learning from cross-country comparisons. J Am Med Inform Assoc 2017;24(02):371-379
17 World Health Organization. From Innovation to Implementation. EHealth in the WHO European Region(2016). Available at: https://www.euro.who.int/_data/assets/pdf_file/0012/302331/ From-Innovation-to-Implementation-eHealth-Report-EU.pdf. Accessed July 15, 2020

18 Esdar M, Hüsers J, Weiß JP, Rauch J, Hübner U. Diffusion dynamics of electronic health records: a longitudinal observational study comparing data from hospitals in Germany and the United States. Int J Med Inform 2019;131:103952

19 Naumann L, Esdar M, Ammenwerth E, Baumberger D, Hübner U. Same goals, yet different outcomes: analysing the current state of ehealth adoption and policies in Austria, Germany, and Switzerland using a mixed methods approach. Stud Health Technol Inform 2019;264:1012-1016

20 Tsai $\mathrm{CH}$, Koch S. Towards a framework for national ehealth evaluation and monitoring: a combined top-down and bottomup approach using sweden as example. Stud Health Technol Inform 2019;264:954-958

21 Price M, Lau F. The clinical adoption meta-model: a temporal meta-model describing the clinical adoption of health information systems. BMC Med Inform Decis Mak 2014;14(01):43

22 Winter A, Haux R, Ammenwerth E, Brigl B, Hellrung N, Jahn F. Health Information Systems: Architectures and Strategies. 2nd ed. New York, NY: Springer-Verlag; 2011 
Appendix 1 Explanations provided for the eHealth indicator AH Access of health care professionals to their patients' health record data for each country

\begin{tabular}{|c|c|}
\hline Argentina & $\begin{array}{l}\text { In } 2018 \text { the Ministry of Health in Argentina presented the National eHealth Strategy 2018-2024, defining } \\
\text { interoperability standards based on HL7 FHIR and SNOMED CT. During } 2018 \text { and } 2019 \text { the ministry worked with all the } \\
\text { provinces to facilitate the adoption of the eHealth strategy, and by the end of } 201917 \text { of the } 24 \text { provinces were } \\
\text { connected to the National Digital Health Network, sharing identification details for more than } 2 \text { million patients. } \\
\text { For } 2020 \text { it is expected that the private sector will start connecting to the Digital Health Network and that the first } \\
\text { transactions of Digital Health Documents will occur, allowing to access patients' cross-institutional health record data } \\
\text { at the national level. The adoption in the public sector is spurred by economic incentives to the provincial ministries of } \\
\text { health, in programs cofunded by the national government and the World Bank. } \\
\text { Each province has defined an adoption plan, that usually starts with a few selected healthcare facilities in the } \\
\text { provincial capital, and then gradually expands to the rest of the province, managing costs for scaling in infrastructure, } \\
\text { change management teams, etc. The current state of advance in } 2020 \text { varies greatly, with a few provinces with more } \\
\text { than } 90 \% \text { coverage of EHR, and some that are just starting the process. } \\
\text { Legacy software used for national immunization registries, communicable diseases, and other public health reports is } \\
\text { slowly being integrated into the National Digital Health Network using new FHRI APIs. } \\
\text { More details on the eHealth Strategy, standards, and national federated identity system are available at: https://www. } \\
\text { argentina.gob.ar/salud/digital }\end{array}$ \\
\hline Australia & 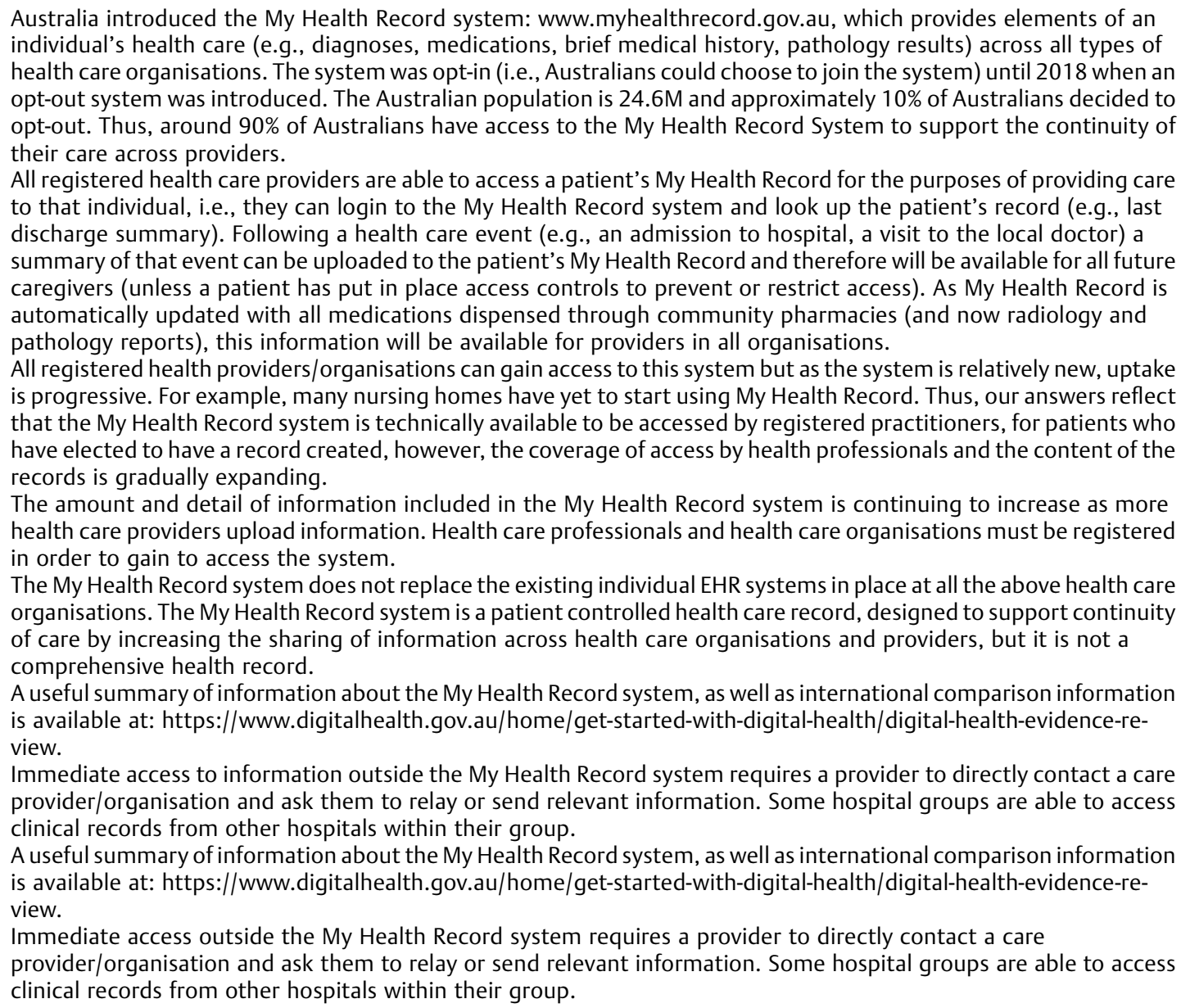 \\
\hline Austria & $\begin{array}{l}\text { In August 2019, all hospitals, approximately 5,000 of 10,000 medical offices and approximately 1,000 of 1,400 } \\
\text { pharmacies were connected to the nationwide Austrian EHR (ELGA;https://www.ots.at/presseaussendung/ } \\
\text { OTS_20190802_OTS0085/elga-e-medikation-im-zeitplan). } \\
\text { Rollout of ELGA component "eMedication" started in February 2018. Medication data can be recorded by medical } \\
\text { offices (prescriptions) and by pharmacies (dispensing). } \\
\text { Diagnoses and problems are only accessible if documented during an inpatient hospital visits in the ELGA discharge } \\
\text { letter. } \\
\text { Pharmacists may only access medication data in ELGA. }\end{array}$ \\
\hline Finland & Regarding pharmacies, the assessment relates to ePrescription which is compiled in the EHR. \\
\hline Germany & $\begin{array}{l}\text { Since October 2016, there is a law in Germany (abbreviated as eHealth-law;available at: https://www. } \\
\text { bundesgesundheitsministerium.de/service/begriffe-von-a-z/e/e-health-gesetz.html) stating that some patients can } \\
\text { receive a medication plan (Medikationsplan). This medication plan is still paperbased (although machine-readable }\end{array}$ \\
\hline
\end{tabular}

(Continued) 
Appendix 1 (Continued)

\begin{tabular}{|c|c|}
\hline & $\begin{array}{l}\text { through bar code). As only a selected group of patients can receive such a medication plan and as until now, as it is } \\
\text { paper-based, the requested immediate access is hardly given, we decided to continue to enter a "-" at medication. }\end{array}$ \\
\hline Hong Kong & $\begin{array}{l}\text { All those }++ \text { are only referred to those who opt-in to use the system, including doctors, nurses, pharmacists for the } \\
\text { records of those patients who have opt-in to share their records. }\end{array}$ \\
\hline Israel & $\begin{array}{l}\text { In Israel, all the population has health insurance provided by four Health Maintenance Organizations (HMOs): Clalit } \\
\text { ( } 52.2 \% \text { of the population), Maccabi ( } 25.4 \% \text { of the population), Me'uhedet ( } 13.9 \% \text { of the population), and Le'umit } \\
\text { ( } 8.5 \% \text { of the population). For example, the HMO Clalit runs over } 1,300 \text { primary care clinics as well as a network of } \\
\text { pharmacies and dental clinics. } \\
\text { Hospitals: this information is available to citizens insured by Clalit and Maccabi ( } 77.6 \% \text { of the population). } \\
\text { Infrastructure already exists to provide this information to all hospitals and is awaiting full implementation. } \\
\text { Nursing homes: If the nursing home belongs to an HMO, then yes (++). Otherwise, no. Private elderly homes } \\
\text { sometimes have an in-house physician. If this is the case, then the Maccabi HMO ( } 25.4 \% \text { of the population) shares } \\
\text { relevant information with the physician. With the rest of the HMOs, the communication is done via the telephone and } \\
\text { is dependent on the goodwill of the primary care physician. } \\
\text { Pharmacies do not see the diagnoses. There are two types of pharmacies: private and ones that belong to the various } \\
\text { HMOs. The ones that belong to the HMO see problems. In Clalit HMO's pharmacies, there is a system that checks } \\
\text { whether there is a conflict in the medication prescribed and the pharmacist is alerted. In Maccabi ( } 25.4 \% \text { of the } \\
\text { population), all pharmacies (private and owned) are alerted. }\end{array}$ \\
\hline Japan & For all "problem" data, they are stored in each professional's record, but they are not compiled in one. \\
\hline Jordan & $\begin{array}{l}\text { Public hospitals do have access through the national health information system Hakeem. Private hospitals do not have } \\
\text { access. } \\
\text { Neither nursing homes nor outpatient nursing organizations exist in Jordan, with some exceptions in the private } \\
\text { sector. Nursing care is typically provided in hospitals. }\end{array}$ \\
\hline Kenya & $\begin{array}{l}\text { There is wide variability in the implementation of systems across facilities. Some facilities have well-functioning point- } \\
\text { of-care electronic record systems, while others do not have systems in place, e.g., they still use paper-based systems. } \\
\text { It is also observed that some facilities, like nursing homes, tend to be behind in adoption electronic record systems. }\end{array}$ \\
\hline South Korea & $\begin{array}{l}\text { Korean government initiated the health information exchange project between primary, secondary, and tertiary care } \\
\text { facilities in Korea. Those hospitals and medical officers participating in this program can exchange patient } \\
\text { information. In 2017, there were } 1,332 \text { care facilities participating with six data depositories and } 11 \text { base hospitals. As } \\
\text { of June } 2018,2,316 \text { care facilities participating with } 10 \text { data depositories and } 15 \text { base hospitals. }\end{array}$ \\
\hline Sweden & $\begin{array}{l}\text { Hospital physicians, primary care physicians, and nurses can access health record data through the Swedish Summary } \\
\text { Care Record ("NationellPatientöversikt," NPÖ). Regions can either act as producers or consumers of NPÖ. All regions } \\
\text { are connected to NPÖ today. However, the data sets published through NPÖ vary from region to region. To date, all } \\
\text { regions publish diagnoses and daily notes. However not all publish medications and risk factors. } \\
\text { Nursing homes in Sweden belong to municipalities. To date, } 250 \text { out of } 290 \text { municipalities are connected to NPÖ and } \\
\text { nurses can thus, with the patient's consent, access health record data if their municipality is connected. Thus for } \\
\text { nursing homes and outpatient nursing organizations, data access depends on whether these municipalities or } \\
\text { privatelybased or regional organizations are connected to the national health information exchange platform } \\
\text { through which the data for the summary care record (NPÖ) can be accessed. A current list of connected regions and } \\
\text { municipalities and the accessible data sets are available at: https://www.inera.se/tjanster/nationell-patientover- } \\
\text { sikt-npo/Nationell-patientoversikt/\#0e1cfb38-259d-42e6-a35d-7fc187152895. } \\
\text { For access to medication data, there exists a second alternative. The Swedish eHealth Agency provides a national } \\
\text { medication list, which contains all prescribed drugs for a patient (available at: https://www.ehalsomyndigheten.- } \\
\text { se/tjanster/prof/register/lakemedelsforteckningen/). The list is aggregated from data of all pharmacies for the last } \\
15 \text { months. Access for physicians and pharmacists to these data is dependent on patient consent. Nurses can access } \\
\text { data in emergency situations with patient consent. }\end{array}$ \\
\hline Turkey & $\begin{array}{l}\text { In order to have a nationalEHR, a citizen must sign into e-Pulse (e-Nabız) web page or its mobile app with their citizen } \\
\text { number (https://enabiz.gov.tr/). They can decide about the privacy of their data using the settings in e-Pulse system. } \\
\text { The privacy options are; "No physician can see my information," "Family physicians can see my information," "The } \\
\text { physician who performed my examination can see my information," "Every physician in the health facility where I had } \\
\text { my examination can see my health information," and "All the physicians of the Ministry of Health can see my } \\
\text { information." } \\
\text { By August } 2019,12,684,955 \text { of } 81 \text { million Turkish citizens ( } 16 \%) \text { had an e-Pulse account. Allergy and emergency care } \\
\text { notes can be entered only by the patient. The national system does not import such data from health institutions. All } \\
\text { hospitals and public medical offices have integration to e-Pulse system. Private offices are not integrated into the } \\
\text { system. The patient can share their data with any other citizen. Physicians in private offices, all nurses and other health } \\
\text { professionals can access data only with the special consent of the patient, as can other citizens. Pharmacists can see all } \\
\text { the diagnoses and prescriptions of the patient. }\end{array}$ \\
\hline United States & $\begin{array}{l}\text { Engagement in four interoperability domains, sending, receiving, finding, and integrating, has continued to rise among U.S. } \\
\text { hospitals although engagement lags among small, rural and critical access hospitals. }{ }^{1} \text { Despite this growth, data access by } \\
\text { healthcare providers was scored as partial in the United States for hospitals and medical offices because interoperability for } \\
\text { immediate access to major relevant data remains siloed, primarily within healthcare systems, EHR vendors, or pockets of } \\
\text { health information exchanges. For example, the federal government is supporting interoperability between The } \\
\text { Department of Veterans Affairs (VA) and the Department of the Defense (DoD) through the Joint Legacy Viewer, }{ }^{2} \text { a web- }\end{array}$ \\
\hline
\end{tabular}




\begin{tabular}{|c|c|}
\hline & 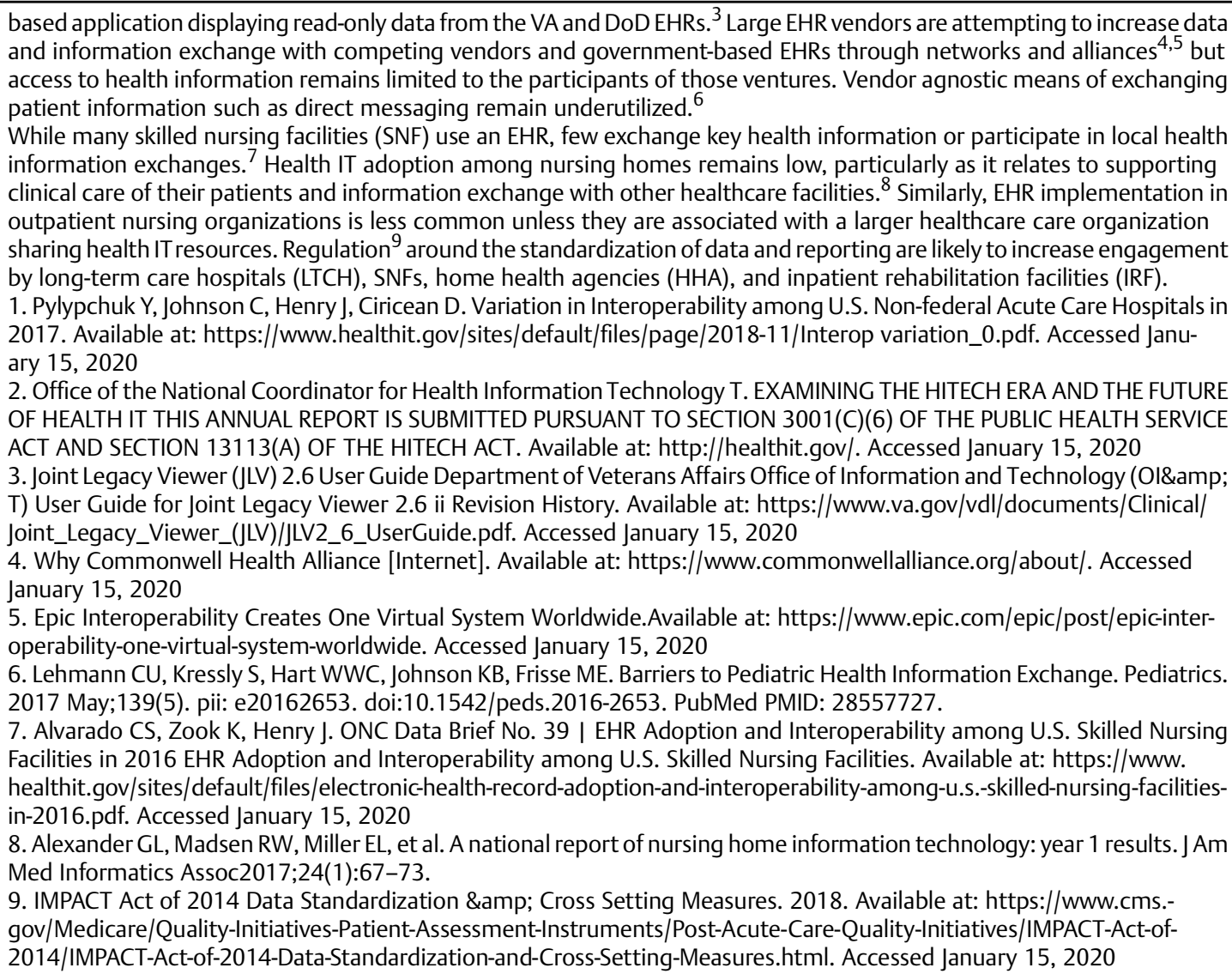 \\
\hline & $\begin{array}{l}\text { pplication programming interfaces; ELGA, Elektronische Gesundheitsakte; EHR, electronic health record; FHIR, } \\
\text { perability Resources; HL7, Health Level Seven; HMO, health maintanance organization; SNOMED CT: Systematized } \\
\text { dicine - Clinical Terms EHR, electronic health record; HMO, health maintanance organization. }\end{array}$ \\
\hline
\end{tabular}

Appendix 2 Explanations provided for the eHealth indicators AP (access of patients to their health record data) and AC (access of caregivers tothe patients' health record data) for each country

\begin{tabular}{|l|l|}
\hline Argentina & $\begin{array}{l}\text { There are some hospitals with EHR where patients access their EHRs to manage appointments and medications, or } \\
\text { where caregivers can do this for the patient. }\end{array}$ \\
\hline Australia & $\begin{array}{l}\text { Patients, who elected to have a My Health Record can directly access their health information. However, the amount } \\
\text { and detail of information available are entirely dependent upon whether health care providers and organisations have } \\
\text { uploaded information (e.g., hospital discharge summary, general practitioner provided information). Some } \\
\text { information is automatically uploaded for all patients, who have a My Health Record, for example, medications } \\
\text { dispensed by community pharmacists, some radiology and pathology results are automatically uploaded. Further } \\
\text { information about the system is available on the website. } \\
\text { Important features to note are that patients can elect for some documents not to be able to be viewed by a specific } \\
\text { provider or health care organisation, e.g., patients can restrict access to some information in their record; patients } \\
\text { may also delete documents from their My Health Record. All original health care documents remain in the individual } \\
\text { health care organisations'EHR. } \\
\text { Outside the My Health Record system patients can seek to access information from health care organisations such as } \\
\text { hospitals, however, this requires a formal request process which can take some time. } \\
\text { If an individual patient has nominated a carer or family member to have access to their My Health Record then they } \\
\text { will be able to access the information in the record as well. Because medication data generated by pharmacies } \\
\text { dispensing mediations is automatically uploaded into My Health Record. However, caregivers would need to have } \\
\text { permission to access their "relatives" record to view this information. }\end{array}$ \\
\hline Austria & $\begin{array}{l}\text { Diagnoses and problems are only accessible if documented during an inpatient hospital visits in the national EHR } \\
\text { "ELGA" discharge letter. } \\
\text { Medication data can only be recorded by medical offices (prescriptions) and by pharmacies (dispensing). Discharge } \\
\text { medication and medication given during the hospital stay can be documented in the ELGA discharge letter. }\end{array}$ \\
\hline
\end{tabular}


Appendix 2 (Continued)

\begin{tabular}{|c|c|}
\hline Finland & $\begin{array}{l}\text { Access by patients is possible through KANTA (Finnish National Data Respository) services. } \\
\text { Access by caregivers is given through KANTA (Finnish national data repository), if (and only if) patients gave } \\
\text { permission for this access. }\end{array}$ \\
\hline Germany & No comment \\
\hline Hong Kong & No comment \\
\hline Israel & $\begin{array}{l}\text { In Israel, there is an ongoing implementation of various applications, mainly by hospitals. These applications make } \\
\text { medical information more accessible to the patient, but these applications are usually built around specific } \\
\text { procedures that are performed in hospitals (e.g., CT, MRI, and ultrasound), but they do not provide access to the } \\
\text { medical records. } \\
\text { All relevant information is available through community care. Patients can access this information anywhere they are, } \\
\text { but the organization that provides and maintains this information is the HMO. Patients can, for example, access } \\
\text { health information that records interactions, diagnosis, and measurements that were recorded by the personnel in } \\
\text { their healthcare organization. } \\
\text { Patients cannot access information from the hospital through their healthcare organization portal. They can receive if } \\
\text { they ask for it, a report from the hospital, but they do not have access to the medical records collected by the hospital. } \\
\text { Caregivers can receive authorization to access the medical information of the patient. This can be done legally } \\
\text { through the institution of a guardian (e.g., parents to their children). In this case, caregivers get a view of the } \\
\text { information the patient can access. However, medical information that is redeemed confidential and private is not } \\
\text { accessible to the caregiver, e.g., parents will not see pregnancy information of their children, caregivers cannot view } \\
\text { AIDS diagnosis and information related to the psychiatric history and condition of the patient, etc. }\end{array}$ \\
\hline Japan & Only a few regional health system institutes ( $2-5 \%$ of the whole country) offer this access. \\
\hline Jordan & No comment \\
\hline Kenya & No comment \\
\hline South Korea & $\begin{array}{l}\text { Access is given through the National Health Insurance Agency of South Korea, if (and only if) patients gave permission } \\
\text { to caregivers for this access. It is then the same access as for patients, as the patients' user identity has to be used. }\end{array}$ \\
\hline Sweden & $\begin{array}{l}\text { Patients can access their health record data through a patient accessible EHR (“Journalen"). As with NPÖ data is } \\
\text { published through the national health information exchange platform and accessibility of the data for the patient.is } \\
\text { steered by the regions' willingness to publish the data. To date, all regions are connected to the national health } \\
\text { information exchange platform and all regions but one publish diagnoses. All regions publish daily notes but less than } \\
\text { half of the regions publish data about allergies. A current overview of the published data is available at: https://www. } \\
\text { inera.se/tjanster/journalen/Journalen/\#7f7bcaef-c5f1-4488-8992-d594b945a166. All patients have access to their } \\
\text { medication data by accessing the national medication list (available at: https://www.ehalsomyndigheten.se/tjanster/ } \\
\text { prof/register/lakemedelsforteckningen/) even if the regions do not publish individual prescription data through } \\
\text { "Journalen". } \\
\text { Note: Caregivers' (i.e., relatives', next-of-kin's) access to the patient's EHR is prohibited by law. An application can be } \\
\text { issued by a caregiver to become a legal proxy. If approved the caregiver has access to the same data as the patient } \\
\text { him/herself. The only exception is that parents/custodians of children under the age of } 13 \text { are granted access to their } \\
\text { children's records. }\end{array}$ \\
\hline Turkey & $\begin{array}{l}\text { Public medical offices have integration to e-Pulse system. Private offices are not integrated into the system. The } \\
\text { national health system imports data that are related to physician diagnoses and prescriptions. If an outpatient nursing } \\
\text { organization is not employing physician(s), their data are not visible. } \\
\text { The patient can share their data with any other citizen. }\end{array}$ \\
\hline United States & $\begin{array}{l}\text { For the United States, hospitals and medical offices are designated as partially given for patient access. While most } \\
\text { hospitals and medical offices use EHRs which include a patient portal allowing patients to view major relevant data, }{ }^{1} \\
\text { patients commonly see clinicians across different health care systems requiring them to maintain access across } \\
\text { multiple disparate patient portals with no interoperability between them. } \\
\text { Apple is attempting to bridge this gap with the health records functionality announced in early } 2018 \text {. }^{2} \text { Currently, in } \\
\text { beta testing with participating U.S. institutions, health records aggregates health data from across EHR platforms and } \\
\text { presents it to patients in the Apple Health application on an iPhone. While there may be pockets of nursing homes, } \\
\text { skilled nursing facilities and outpatient nursing organizations with patient portals, }{ }^{3,4} \text { particularly when those } \\
\text { organizations are associated with a larger healthcare system, the majority of patient portals are implemented } \\
\text { through hospitals and medical offices. } \\
\text { In the United States, caregiver access is achieved through designation as a delegate in the patient portal. Therefore, } \\
\text { caregivers generally have the same access to health data as patients once they are granted delegate privileges. When } \\
\text { receiving care outside of a single healthcare system, patients and their caregivers need to maintain to access multiple } \\
\text { different patient portals without an aggregated view of health data in any single portal. For this reason, caregiver } \\
\text { access to patient data is set as partially given. } \\
\text { 1. Osborn CY, Rosenbloom ST, Stenner SP, et al. MyHealthAtVanderbilt: policies and procedures governing patient } \\
\text { portal functionality. J Am Med Informatics Assoc2011;18(Supplement 1):i18-23. Available at: https://academic.oup. } \\
\text { com/jamia/article-lookup/doi/10.1136/amiajn-2011-000184. } \\
\text { 2. Healthcare - Health Records - Apple. Available at: https://www.apple.com/healthcare/health-records/. Accessed } \\
\text { January 15, 2020 } \\
\text { 3. Alvarado CS, Zook K, Henry J. ONC Data Brief No. } 39 \text { I EHR Adoption and Interoperability among U.S. Skilled } \\
\text { Nursing Facilities in } 2016 \text { EHR Adoption and Interoperability among U.S. Skilled Nursing Facilities. 2016. Available }\end{array}$ \\
\hline
\end{tabular}




\begin{tabular}{|l|l|}
\hline & $\begin{array}{l}\text { from: https://www.healthit.gov/sites/default/files/electronic-health-record-adoption-and-interoperability-among-u. } \\
\text { S.-skilled-nursing-facilities-in-2016.pdf. Accessed January 15, } 2020 \\
\text { 4. Alexander GL, Madsen RW, Miller EL, et al. A national report of nursing home information technology: year } 1 \text { results. } \\
\text { J Am Med Informatics Assoc 2017;24(1):67-73. }\end{array}$ \\
\hline $\begin{array}{l}\text { Abbreviations: CT, computed tomography, EHR, electronic health record; HMO, health maintanance organization; MRI, magnetic } \\
\text { resonance imaging; NPÖ,NationellPatientöversikt. }\end{array}$
\end{tabular}

Appendix 3 Explanations provided for the eHealth indicator EH (enabling health care professionals to add data to their patients' health record[s]) for each country

\begin{tabular}{|c|c|}
\hline Argentina & $\begin{array}{l}\text { There are some healthcare organizations with EHRs where physicians, nurses, and pharmacists add data to their } \\
\text { patients' EHRs. }\end{array}$ \\
\hline Australia & $\begin{array}{l}\text { All registered health care providers can add information to a patient's My Health Record. This would occur at the end } \\
\text { of a health event. } \\
\text { Most hospitals etc. have an EHR system of some form in their organisation. Community pharmacists have their own } \\
\text { electronic information systems where they record medications dispensed. However, we would not call this an EHR } \\
\text { system and such systems are not connected to hospital EHRs. Thus, they add medication data to a record system and } \\
\text { such data is also associated with obtaining subsidies for some medications. } \\
\text { Specialist doctors, who work in their own practices (as well as in hospitals), have their own medical record systems and } \\
\text { most of these are not computerised. Probably around } 30-50 \% \text { of nursing homes have some form of computerised data } \\
\text { collection system but these range from those with very basic clinical information to those with clinical notes and } \\
\text { medication components. However, our family/general practitioners in the community are highly computerised with } \\
\text { all having electronic record systems in their practices. } \\
\text { Hence, it is quite difficult to give overall scores for this question and the record systems of these various groups are } \\
\text { separate from each other. The national health record allows practitioners to choose to upload some summary } \\
\text { information in defined templates. } \\
\text { Comments on some outcomes: } \\
\text { Medical offices: ++ for family physicians in the community, + for specialist physicians, overall: ++ } \\
\text { Nursing homes: + varies a lot. Maybe around } 40-50 \% \text { have some sort of EHR system. } \\
\text { Outpatient nursing organizations: + Once again varies considerably between organisations. } \\
\text { Pharmacies: + Yes they have systems for managing the dispensing of medications but I would not normally classify } \\
\text { this as an EHR. }\end{array}$ \\
\hline Austria & $\begin{array}{l}\text { Hospital pharmacists do not record medication data in Austria. } \\
\text { Most medical offices use computer-based documentation systems. } \\
\text { Most nursing homes use a mix of paper-based and computer-based documentation systems. } \\
\text { In August } 2019 \text {, about } 1,000 \text { of } 1,400 \text { pharmacies were connected to ELGA; this indicates that they have an } \\
\text { institutional EHR. }\end{array}$ \\
\hline Finland & Pharmacists: only ePrescription \\
\hline Germany & $\begin{array}{l}\text { Hospital pharmacists can add data indirectly through medication recommendations to physicians, plus own (but } \\
\text { separate) documentation. } \\
\text { Nursing homes and outpatient nursing organizations only have some rare documentation in EHRs. At the current very } \\
\text { limited state it has, however, clearly to be rated as not given. } \\
\text { Not in all pharmacies can add data, and sometimes only for selected patients. }\end{array}$ \\
\hline Hong Kong & $\begin{array}{l}\text { Nurses in hospitals can add summaries, but not drugs or allergies or diagnoses. Pharmacists in hospitals can add or } \\
\text { amend drugs but not other information. Outpatient nursing organizations can add summaries only }\end{array}$ \\
\hline Israel & $\begin{array}{l}\text { All healthcare professionals work on the health record and can view or add information into it according to their } \\
\text { authorization. }\end{array}$ \\
\hline Japan & No comment \\
\hline Jordan & No comment \\
\hline Kenya & $\begin{array}{l}\text { Some facilities have well-functioning point of care systems, while others rely on paper systems or on retrospective } \\
\text { data entry into electronic record systems. While some of these health care institutions might have EHRs with the } \\
\text { ability for providers to enter data into the system, there still is an overwhelming preference by providers to use paper } \\
\text { records in those settings. } \\
\text { Only a small number of }<10 \% \text { of pharmacies have electronic documentation systems to keep patient information, } \\
\text { these are usually programs that are using the EMR endorsed by the country for HIV care and treatment programs. In } \\
\text { addition, private pharmacies also have electronic record systems, but these are mostly for inventory. }\end{array}$ \\
\hline South Korea & $\begin{array}{l}\text { The hospital pharmacist is a hospital affiliate, and the outpatient pharmacist is an independent agency that only } \\
\text { shares drug information. }\end{array}$ \\
\hline Sweden & $\begin{array}{l}\text { All professionals always add data to their local medical record but as data is published through the National Health } \\
\text { Information Exchange platform and viewed through the summary care record (for professionals) or the patient- }\end{array}$ \\
\hline
\end{tabular}


Appendix 3 (Continued)

\begin{tabular}{|l|l|}
\hline Turkey & $\begin{array}{l}\text { accessible EHR (for patients) the data can be made accessible nationally. However, there is not a single integrated } \\
\text { national EHR system in Sweden. }\end{array}$ \\
\hline United States & $\begin{array}{l}\text { Some private offices do not use EHRs. Public outpatient nursing organizations usually work as units of the hospitals. } \\
\text { Nurses can add some data to the patient health records. }\end{array}$ \\
& $\begin{array}{l}\text { Adoption of health IT in nursing homes and outpatient nursing organizations has lagged behind their hospital and } \\
\text { medical office counterparts. }{ }^{1,2} \text { When implemented in nursing homes, health IT is more likely to be used for } \\
\text { administrative and billing activities than to support clinical activities. }{ }^{2} \text { Additionally, while some nursing homes have } \\
\text { the capability to support clinical activities within their EHR, the extent of use of that functionality in daily resident care } \\
\text { is much lower. }\end{array}$ \\
$\begin{array}{l}\text { 1. Alvarado CS, Zook K, Henry J. ONC Data Brief No. 39 I EHR Adoption and Interoperability among U.S. Skilled } \\
\text { Nursing Facilities in } 2016 \text { EHR Adoption and Interoperability among U.S. Skilled Nursing Facilities. Available at: } \\
\text { https://www.healthit.gov/sites/default/files/electronic-health-record-adoption-and-interoperability-among-u.s.- } \\
\text { skilled-nursing-facilities-in-2016.pdf. Accessed January 15, 2020 } \\
\text { 2. Alexander GL, Madsen RW, Miller EL, et al. A national report of nursing home information technology: year } 1 \text { results. } \\
\text { J Am Med Informatics Assoc15];24(1):67-73. }\end{array}$ \\
\hline Abbreviations: EHR, electronic health record; EMR, electronic medicalrecord; IT, information technology.
\end{tabular}

Appendix 4 Explanations provided for the eHealth indicator eHealth indicators EP (enabling patients to add data to their health record $[s]$ ) and EC (enabling caregivers to add data to the patients' health record[s]) as for each country

\begin{tabular}{|c|c|}
\hline Argentina & $\begin{array}{l}\text { There are some hospitals with EHRs where patients access their EHRs and add some vital signs and some medical } \\
\text { reports. } \\
\text { There are also some hospitals with EHRs where caregivers access patient EHRs and add some vital signs and some } \\
\text { medical reports. }\end{array}$ \\
\hline Australia & $\begin{array}{l}\text { Through the My Health Record system, patients can add information but this functionality is quite limited at the } \\
\text { moment. For example, they can upload an "advanced care directive." } \\
\text { Patients cannot immediately add information to other EHRs, e.g., in hospital. } \\
\text { Caregivers, who have been allocated permission by the patient, can act on behalf of the patient, e.g., a parent on } \\
\text { behalf of a child. In this designated role, the caregiver can access the My Health Record system using the same } \\
\text { functionality as described above. However, as stated there is quite limited functionality in the national my health } \\
\text { record system for patients or their caregivers to add information. } \\
\text { There is no facility for caregivers to provide input to EHR systems for individual provider organisations such as } \\
\text { hospitals, nursing homes, etc. }\end{array}$ \\
\hline Austria & No comment \\
\hline Finland & Through KANTA services \\
\hline Germany & No comment \\
\hline Hong Kong & No comment \\
\hline Israel & $\begin{array}{l}\text { Maccabi HMO ( } 25.4 \% \text { of the population) has a personal health record (PHR) to which patients can add data, but it is } \\
\text { not integrated with the EHR. Patients can discuss the information they added with the physician during face-to- } \\
\text { face meetings, however, the physician is not responsible to actively view this information or to act upon it on a } \\
\text { regular basis. } \\
\text { See also the preceding comment about caregivers' access to the patient's EHR. }\end{array}$ \\
\hline Japan & No comment \\
\hline Jordan & No comment \\
\hline Kenya & No comment \\
\hline South Korea & No comment \\
\hline Sweden & $\begin{array}{l}\text { Patients can add notes to their EHR but only in one out of } 21 \text { county councils and regions. } \\
\text { For caregivers, access is in general only granted for custodians of children under the age of } 13 \text { years. Otherwise not } \\
\text { allowed for caregivers unless an official application has been filed by the caregiver and been granted by the county } \\
\text { council. In that case, it is the same as for patients. }\end{array}$ \\
\hline Turkey & $\begin{array}{l}\text { Patients can add only their weight, height, allergies, blood pressure, blood sugar, heart rate, and emergency notes. } \\
\text { Caregivers can add data if the patient is below } 18 \text { years old. }\end{array}$ \\
\hline The United States & $\begin{array}{l}\text { For the United States, this indicator is set at partial because most patient portals contain functionality that allows } \\
\text { patients to enter data }{ }^{1} \text { but typically only for a subset of predefined structured data elements and occasionally only } \\
\text { by invitation from their healthcare provider. Data that are commonly patient-entered include medications and } \\
\text { other discrete data elements such as blood pressure or blood glucose readings. However, as the adoption of } \\
\text { wearable technology increases, the manual process of entering multiple data values disincentivizes some patients, }\end{array}$ \\
\hline
\end{tabular}


Appendix 4 (Continued)

\begin{tabular}{|c|c|}
\hline & $\begin{array}{l}\text { who now have numerous vital sign readings or glucose monitoring results to share with their physician. Some EHRs } \\
\text { also supports the ability to upload additional clinical data such as a photograph to share with their physician } \\
\text { securely through the EHR or to fill out previsit forms for easier integration at the time of the in-person interaction } \\
\text { but these are not universally available features and are not always implemented at institutions even when the } \\
\text { technical capability exists. } \\
\text { Caregivers typically have the same data-entry rights as patients once they are granted delegate privileges in the } \\
\text { patient portal. Therefore, they too subject to the limitations of predefined data subsets when entering data } \\
\text { through the patient portal. } \\
\text { 1. Most Wired Hospitals Use Technology for a Better Patient Experience I AHA.; Available at: https://www.aha.org/ } \\
\text { press-releases/2016-07-06-most-wired-hospitals-use-technology-better-patient-experience. Accessed January 15, } \\
2020 \text {. }\end{array}$ \\
\hline
\end{tabular}

